when: pathologists used this finding of patchiness as a strong mandate for the diagnosis of Crohn's disease; or surgeons became reluctant to do proctocolectomies in ulcerative colitis cases that were indicated clinically, because they were fearful that patchiness of involvement meant Crohn's disease. As the armamentarium of immunomodulatory drugs expands, more specific to one disease than the other, it is critical to recognise this important diagnostic feature of ulcerative colitis.

Our findings were in patients with documented ulcerative colitis whereas Levine $e t$ al found predominately normal or borderline biopsies among patients with ulcerative proctitis (10 of 11 cases) rather than ulcerative colitis. Although we have shown that over time rectal biopsies from patients with ulcerative proctitis are indistinguishable from biopsies from patients with ulcerative colitis, ${ }^{3}$ it remains a possibility that these diseases may have different pathophysiology. Nonetheless, it is important to realise that in ulcerative proctitis, rectal biopsies may normalise over time. The presence of frankly normal rectal histology in patients with longstanding diagnoses of ulcerative colitis or proctitis often raises the issue of the accuracy of the initial diagnoses. We support Levine et al in their contention that these diseases are dynamic in their expression patterns, and this fact should now be accepted into the new diagnostic dogma of ulcerative colitis.

Why has the conventional wisdom of absolute rectal involvement, and absolute disease continuity in ulcerative colitis persisted so long? We believe that it points to the selectivity of human observation. We only look for what we believe we should find. Patchy rectosigmoid involvement in ulcerative colitis is one example, but an even more compelling one is how Helicobacter pylori could be missed in gastric biopsy tissue sections for so long, by so many!

CHARLES N BERNSTEIN Section of Gastroenterology, University of Manitoba Winnipeg, Manitoba, Canada

FERGUS SHANAHAN Department of Medicine, University of Cork, Wilton, Cork, Ireland

WILFRED M WEINSTEIN

Division of Digestive Diseases, UCLA School of Medicine, Los Angeles, California, USA

1 Levine TS, Tzardi M, Mitchell S, Sowter C, Price AB. Diagnostic difficulty arising from rectal recovery in ulcerative colitis. $\mathcal{F}$ Clin Pathol 1996;49:319-23.

2 Bernstein CN, Shanahan F, Anton PA, Weinstein WM. Patchiness of mucosal inflammation in treated ulcerative colitis: A prospective study. Gastrointest Endosc 1995;42:232-7.

3 Bernstein CN, Surawicz CM, Bronner M, Weinstein WM. Is follicular proctitis a distinct Weinstein WM. Is follicular proctitis a distinct
form of ulcerative proctitis? Gastroenterology 1994;106:A652.

\section{Rights of possession in human corpses}

English law fails to recognise any right to possession of a corpse as the corpse is not a chose in action. This means-for example, it cannot be stolen.

However, what is not commonly recognised is that the executors may have the right to dispose of the body according to the terms of the deceased's will. Any interference in this right - such as removing the body (or as we laymen might say, "stealing it") may raise a cause of action under the Law of Property Act 1925. This point has been made at least since Glazebrook lectured on criminal law at Cambridge in the early ' 70 s.

The legal rule that a body cannot be stolen commonly generates a belief that no other cause of action can possibly arise, although the example above shows that it can. The editorial team of the fournal of Clinical Pathology is to be congratulated in disabusing their readership of this common misconception.

OLIVER DEARLOVE Department of Anaesthesia, Royal Manchester Children's Hospital, Pendlebury M25 2AE, United Kingdom

1 Hudson M. Rights of possession in human corpses [editorial]. $\mathcal{F}$ Clin Pathol 1997;50:90-1.

\section{Proliferation indexes-a comparison between cutaneous basal and squamous cell carcinomas}

We read with interest the article by $\mathrm{Al}-$ Sader et al that compared cell proliferation indexes in cutaneous basal cell carcinomas (BCC) and squamous cell carcinomas (SCC). ${ }^{1}$ We have evaluated silver-stained nucleolar organiser region (Ag-NOR) protein quantity, proliferating cell nuclear antigen (PCNA) labelling index, and mitotic index in the corresponding spontaneous canine cutaneous tumours obtaining comparable results. ${ }^{23}$ However, more recently, in an attempt to explain the paradoxical clinical behaviour of canine cutaneous BCC, we obtained interesting results studying the combined behaviour of mitotic index, apoptotic index, and mitotic phase distribution in the aforementioned tumours. ${ }^{4}$ In fact, in accordance with Brown and Gatter for human BCC, ${ }^{5}$ our results strongly suggest that a prolonged " $\mathrm{M}$ phase" of the cell cycle plays an important role in maintaining a slow rate of growth in canine BCC. The strong similarity between canine and human BCC and SCC support the opinion that spontaneous animal tumours could represent useful models for human disease.

$P$ MAIOLINO G DE VICO

Dipartimento di Patologia di Profilassi e di Ispezione degli Alimenti Sezione di Anatomia Patologica Facoltà di Medicina Veterinaria Università degli Studi di Napoli "Federico II" Via F Delpino, 1-80137, Napoli

1 Al-Sader MH, Doyle E, Kay EW, Bennett M, Barry Walsh C, Curran B, et al. Proliferation indexes-a comparison between cutaneous basal and squamous cell carcinomas. $₹$ Clin Pathol 1996;49:549-51.

2 De Vico G, Agrimi U, Maiolino P. Nucleolar size and mitotic index in basal cell carcinomas (BCC) and squamous cell carcinomas (SCC) (BCC) and squamous cell carcinomas (SCC) 9 of can

3 Maiolino P, Restucci B, De Vico G. Expression of proliferating cell nuclear antigen in basal cel carcinomas and in squamous cell carcinomas of canine skin: correlation with mitotic index and histological features. $\mathcal{F ~ A m}$ Vet Med Assoc 1995;42:339-43.

4 Maiolino P, De Vico G. Mitotic phase distribution, mitotic activity and apoptosis in basal cell tumours of canine skin. $\mathcal{F}$ Am Vet Med Assoc [in press].
5 Brown DC, Gatter KC. Monoclonal antibody $\mathrm{Ki}-67$ : its use in histopathology. Histopatholog 1990;17:489-503.

Brain tissue banks in psychiatric and neurological research

We welcomed the article by Cairns and Lantos on brain tissue banks. 'The importance of such facilities in psychiatric and neurological research has not been adequately appreciated by the wider clinical community, perhaps because collection and storage of postmortem tissue for research is not as an emotive issue as requesting organs for donation. However, without such tissue banks little would be known about many debilitating conditions.

The South West Brain Bank in Bristol was established over 10 years ago to collect brain tissue from people suffering from dementia. It is from this experience that we write to emphasise certain points that are important not only to potential donors and their relatives but also to the physicians requesting the donation, and those using the tissue for research.

Making the decision to donate tissue for research can be a very difficult one for most people. This can be made even more difficult if it is left to the time when loved ones are close to death or have died. It is far preferable that all arrangements are made in advance of the event, and it is helpful if potential donors and their families can be given information about the procedures involved in a donation (perhaps in the form of a leaflet). The details can be assimilated and discussed within the family and with the coordinator of the facility at a time when bereavement does not cloud the issue. We have found the role of the brain bank coordinator to be a crucial one at this stage. We have one person acting as the coordinator, an MLSO trained in neuropathology. She deals with the donation from the initia arrangements through to processing of the tissue for histological assessment.

Before a histological diagnosis is made, the neuropathologist is provided with as complete a clinical history as possible. This is obtained, using a standardised protocol, from all available hospital and general practitioner notes.

The continuing acquisition of tissue for research purposes relies heavily on an understanding of the importance of such donations by the medical practitioners who must make the request and, perhaps more importantly, by their patients and relatives. The responsibility for giving potential donors and their families enough information and support regarding a donation lies with the brain banks who must approach this with compassion and sensitivity.

G K WILCOCK $S$ M MATTHEWS S H MACGOWAN University of Bristol Department of Care of the Elderly Frenchay Hospital, Bristol BS16 1LE

1 Cairns NJ, Lantos PL. Brain tissue banks in psychiatric and neurological research. $f$ Clin Pathol 1996;49:870-3. 
cific clinical settings, transfusion transmitted infections, adverse reactions to transfusion, and new and evolving regimens. The layout is extremely user-friendly with respect to consulting the book on a particular bedside problem. At times, perhaps the enthusiasm for clinical matters is carried a little too far, the summary of surgical techniques used in intrahepatic shunts, which appears in the section on surgical blood saving, is fascinating but possibly superfluous in this presentation. In general though the approach of case orientated discussion works well and, where necessary, sufficient laboratory background is given to enable a good understanding of the problems.

This "background" approach could in places have been further developed with advantage, for instance with the reference, in various sections, to leucocyte reduction. Separated as they are, it is less easy to obtain an overview of the basics and drawbacks of this technique, and a small, specific section dealing with mechanisms of filtration and critical factors in the use of filters would have been useful.

The section on new and evolving regimens brings the reader up to date with the subject dealing with response modifiers, adoptive immunotherapy, gene therapy, and peripheral blood stem cell therapy. This text was prepared at a time when allogenic cord blood transfusion was seen as a topic still under development but with an apparently bright future, so one can confidently expect a development of this theme in the fourth edition of this text. Perhaps one of the greatest virtues of the volume is its comprehensive list of references. Admittedly, with a multiauthor genesis, references may be duplicated, but with 6049 , readers are hardly likely to be frustrated in their search for knowledge. Any book in which the section on platelet therapy begins with an aphorism to the effect that possession of a thorough understanding of platelet transfusion is indicative of confusion rather than confidence, cannot be all bad. This volume is virtually all good and commends itself to anyone taking an active interest in transfusion medicine at a postgraduate level. No self respecting specialist in the subject should be without it.

W WAGSTAFF

Bone Marrow Pathology. 2nd edn. Bain BJ, Clark DM, Lampert IA. (Pp 328; £79.50.) Blackwell Science. 1996. ISBN 0 865426473

It was a pleasure to review the second edition of "Bone Marrow Pathology" knowing how useful the first edition has proved. For those not familiar with the book, it is an ideal practical book for all haematologists and histopathologists involved in reporting bone marrow aspirates and trephines.

It has a clear layout with good quality colour photomicrographs of an appropriate mixture of cytological and histological appearances. The chapters work methodically through the normal marrow, infective and reactive conditions, the various haematological and lymphoid malignancies, disorders of haemopoiesis, metastatic tumours, and bone disorders. There are useful tables and graphs of normal values, grading systems, classification of leukaemias and lymphomas, suitable antibody panels, etc. The text is easy to read and with a wealth of practical comments related to the authors' experience.
If there is any department that reports trephines and does not own the first edition, then the second edition is an essential purchase. I have tried to do a "spot the difference" between the two editions to decide whether owners of the first edition should upgrade. The chapter titles are unchanged and most of the photographs and tables are the same. This is not a major rewrite but there are significant differences in areas such as immunocytochemistry and lymphoma classification. The REAL classification is included and compared with the Kiel and Working Formulation. Useful new antibodies are discussed, and a technical appendix has been added. Several pages are devoted to a new section on artefacts that should be particularly useful to haematologists who are less likely to be familiar with the artefacts common to formalin fixed, paraffin wax embedded sections.

The book emphasises an integrated approach for reaching a diagnosis. There is no place for a histopathologist reporting the trephine in ignorance of the aspirate's appearance but it is also unsatisfactory if the trephine goes straight to the haematologist. The combination of good quality trephine sections and this book should encourage histopathologists to participate in this fascinating and demanding field. Haematologists reading this book will appreciate the additional information that can be gleaned from good quality sections and this may influence their attitude towards taking trephines.

S DILLY

\section{Notices}

\section{Histopathology of the bone marrow}

Wednesday 17 September 1997

Imperial College School of Medicine, St Mary's London, UK

A one day course suitable for career post holders and trainees in haematology and histopathology.

Numbers restricted to 40; CME approved (7 credits); cost $£ 85$ (including lunch).

Apply in writing enclosing a cheque (payable to Imperial College) to Jenny Guy, Postgraduate Course Organiser, Postgraduate Medical Centre, 2nd Floor, Mint Wing, St Mary's Hospital, London W2, UK.

\section{Second meeting of the European Study Group on Molecular Diagnostics}

Wednesday 15 October 1997

Kurhaus Hotel, The Hague, Netherlands

Registration is free.

For further information contact Prof. Dr. M Altwegg, Department of Microbiology, University of Zurich, Gloriastrasse 30, CH-8028 Zürich, Switzerland. (Fax: +41 (1) 2528107 .)

\section{Practical adult cardiovascular pathology course}

Monday 17 November 1997

This practical, hands on course approaches in detail the problems that face diagnostic pathologists when dealing with cardiovascular pathology. The approach to cardiac autopsy and sudden death will be emphasised. Cardiac specimens will be made available for dissection and analysis, and practical demonstrations as well as video demonstrations will be highlighted. A slide seminar is also included. The course is aimed at trainees studying for the MRCPath as well as senior pathologists who wish to update their knowledge.

Course fee: $£ 125$ including coffee, tea and lunch ( $£ 100$ for juniors in training).

For further details contact the National Heart and Lung Institute, Dovehouse Street, London SW3 6LY, UK. (Tel: 0171 351 8172; fax: 0171376 3442.)

\section{Supraregional Assay and Advisory Service}

In response to tenders received, the following laboratories have been designated to offer the Supraregional Assay and Advisory Service:

\section{Porphyrin metabolism}

King's College School of

Medicine and Dentistry, Department of Clinical Biochemistry, Bessemer Road, London SE5 9PJ.

Professor T J Peters, tel: 0171737 3008; fax 01717377434 .

\section{University Hospital of Wales NHS Trust Laboratory, Heath Park, Cardiff CF4 4XW.}

Professor G H Elder, tel: 01222742799 (laboratory); 01222 743565; fax: 01222 766276.

The standard of the responses to the invitations to tender was very high and the Supraregional Assay and Advisory Service Board compliment the laboratories who bid for these assays.

Professor V Marks, Dean of Medicine, Chairman, SAAS Management Executive Board, EIHMS, University of Surrey, Stirling House Campus, Surrey Research Park, Guildford GU2 5RF

\section{Correction}

Proliferation indexes-a comparison between cutaneous basal and squamous cell carcinomas [letter]. Maiolino P, De Vico G. J Clin Pathol 1997;50:355.

Reference 2 in this letter should have read:

De Vico G, Agrimi U, Maiolino P. Nucleolar size and mitotic index in basal cell carcinomas (BCC) and squamous cell carcinomas (SCC) of canine skin. Fournal of Veterinary Medicine series A 1995;42:339-43.

and not as published. The error is regretted. 